\title{
PENGARUH PRINSIP INTEGRITAS, OBJEKTIVITAS DAN PERILAKU PROFESIONAL TERHADAP KUALITAS AUDIT PADA KAP KOTA MAKASSAR
}

\author{
Nur Azizah Basmar \\ Azizah.basmar@gmail.com \\ Prodi Akuntansi/Sekolah Tinggi Ilmu Ekonomi Makassar (STIEM) Bongaya \\ Jl. Let. Jend. Mappaouddang No. 28 Makassar
}

\begin{abstract}
ABSTRAK
Penelitian ini bertujuan untuk mengetahui apakah prinsip integritas, prinsip objektivitas dan prinsip perilaku profesional berpengaruh terhadap kualitas audit pada kantor akuntan publik (KAP) di kota Makassar. Pengumpulan data menggunakan data primer yang diperoleh dari kuesioner dengan menggunakan teknik Nonprobality Sampling (Sampel Jenuh). Populasinya adalah seluruh akuntan publik di kota makassar sejumlah 56 auditor, sedangkan sampel yang diambil berjumlah 56 responden. Hasil kuesioner tersebut telah diuji validitas dan reliabilitasnya, juga telah diuji asumsi klasik berupa asumsi normalitas, asumsi heterokedastisitas, asumsi multikolinieritas dan autokorelasinya. Metode analisis data menggunakan teknik regresi berganda. Hasil penelitian menunjukkan bahwa prinsip perilaku profesional tidak berpengaruh signifikan terhadap kualitas audit, sedangkan prinsip integritas dan prinsip objektivitas berpengaruh signifikan terhadap kualitas audit. Dari hasil tersebut, prinsip integritas dan objektivitas layaknya menjadi perhatian bagi akuntan publik untuk menciptakan kualitas audit yang baik.
\end{abstract}

Kata kunci: Prinsip Integritas; Objektivitas; Perilaku Profesional; Kualitas Audit

\section{ABSTRACT}

This study aimed to determine whether the principles of integrity, objectivity principles, and principles of professional behavior affect audit quality at public accounting firms (KAP) in Makassar. Data collection uses primary data obtained from questionnaires using the Nonprobality Sampling technique. The population was all public accountants in the city of Makassar, totaling 56 auditors, while the sample taken amounted to 56 respondents. The results of the questionnaire have been tested not only for validity and reliability, but also for classic test assumptions in the form of normality assumptions, heteroskedasticity assumptions, multicollinearity, and autocorrelation assumptions. The method of data analysis uses multiple regression techniques. The results showed that the principle of professional behavior had no significant effect on audit quality. In contrast, the law of integrity and objectivity policies had a significant impact on audit quality. From these results, the principle of honesty and objectivity should be a concern for public accountants to create good audit quality.

Keywords: Integrity Principle; Objectivity; Professional Behavior; Audit Quality

\section{PENDAHULUAN}

Pada tahun 1998, Ikatan Akuntansi Indonesia (IAI) merumuskan etika profesional baru yang diberi nama Kode Etik Ikatan Akuntan Indonesia. Etika profesional baru 
ini berbeda dengan etika profesional yang berlaku dalam tahun-tahun sebelumnya. Kode etik Ikatan Akuntan Indonesia (IAI) ini dikembangkan dengan struktur baru. Kompartemen yang dibentuk dalam organisasi IAI terdiri dari 4 macam yaitu Kompartemen Akuntan Publik, Kompartemen Akuntan Manajemen, Kompartemen Akuntan Pendidik, dan Kompartemen Akuntan Sektor Publik.

Akuntan publik atau auditor independen dalam tugasnya mengaudit perusahaan klien memiliki posisi yang strategis sebagai pihak ketiga dalam lingkungan perusahaan klien yakni ketika akuntan publik mengemban tugas dan tanggung jawab dari manajemen (agen) untuk mengaudit laporan keuangan perusahaan yang dikelolanya. Dalam hal ini manajemen ingin supaya kinerjanya terlihat selalu baik dimata pihak eksternal perusahaan terutama pemilik (prinsipal). Akan tetapi disisi lain, pemilik (prinsipal) menginginkan supaya auditor melaporkan dengan sejujurnya keadaan yang ada pada perusahaan yang telah dibiayainya. Dari uraian di atas terlihat adanya suatu kepentingan yang berbeda antara manajemen dan pemakai laporan keuangan (Tjun, dkk, 2012).

Kepercayaan yang besar dari pemakai laporan keuangan auditan dan jasa lainnya yang diberikan oleh akuntan publik inilah yang akhirnya mengharuskan akuntan publik memperhatikan kualitas audit yang dihasilkannya.

Kualitas audit dipengaruhi sikap auditor independen dalam menerapkan Kode Etik Profesi Akuntan Publik. Kode etik ini menetapkan prinsip dasar dan aturan etika profesi yang harus diterapkan oleh setiap individu dalam kantor akuntan publik (KAP) atau Jaringan KAP, baik yang merupakan anggota Ikatan Akuntan Publik Indonesia (IAPI) maupun yang bukan merupakan anggota IAPI.

Terdapat lima prinsip dalam bagian A Kode Etik Profesi Akuntan Publik yaitu prinsip integritas, objektivitas, kompetensi, kerahasiaan, dan perilaku profesional. Dalam penelitian ini, peneliti membahas tiga prinsip pada bagian A dari Kode Etik Profesi Akuntan Publik yaitu prinsip integritas, objektivitas, dan perilaku professional sebab bagian A merupakan unsur-unsur penting yang harus dimiliki seseorang apabila ingin berprofesi menjadi auditor independen.

Integritas mengharuskan seorang anggota untuk, antara lain, bersikap jujur dan berterus terang tanpa harus mengorbankan rahasia penerima jasa sehingga laporan 
yang disajikan itu dapat menjelaskan suatu kebenaran akan fakta, karena dengan cara itulah maka masyarakat dapat mengakui profesionalisme seorang akuntan (Binga dan Jessica 2011).

Setiap praktisi tidak boleh membiarkan subjektivitas, benturan kepentingan, atau pengaruh yang tidak layak (undueinfluence) dari pihak-pihak lain mempengaruhi pertimbangan profesional atau pertimbangan bisnisnya (IAPI, 2008: 100.1). Hal tersebut dijelaskan IAPI sehubungan dengan prinsip objektivitas. Hal ini berarti bahwa seorang auditor independen dalam menjalankan objektivitas harus dapat melaporkan kesalahan yang dilakukan oleh klien tanpa adanya pengaruh dari pihak luar. (binga dan Jessica, 2011).

Menurut Arens \& Loobecke (2009) Profesionalisme adalah suatu tanggung jawab yang dibebankan lebih dari sekedar dari memenuhi tanggung jawab yang dibebankan kepadanya dan lebih dari sekedar dari memenuhi Undang-undang dan peraturan masyarakat.

Penelitian ini bertujuan untuk mengetahui pengaruh prinsip integritas, objektivitas dan perilaku professional terhadap kualitas audit pada Kantor Akuntan Publik yang ada di Kota Makassar.

\section{METODE PENELITIAN}

Pendekatan penelitian yang dilakukan dalam penelitian ini adalah pendekatan kuantitatif dengan studi kasualitas yaitu mengukur dua variabel atau lebih, juga menunjukkan arah hubungan antara variabel bebas dengan variabel terikat (Kuncoro, 2011: 19). Data yang digunakan dalam penelitian ini adalah data primer, Menurut Danang Sunyoto (2011: 22), Data Primer adalah data asli yang dikumpulkan sendiri oleh peneliti untuk menjawab masalah penelitiannya secara khusus. Teknik yang digunakan dalam pengambilan sampel menggunakan teknik Nonprobality Sampling (sampel jenuh). Nonprobality Sampling merupakan teknik penentuan sampel bila semua anggota populasi relative kecil. Sampel jenuh juga biasa disebut sampel yang sudah maksimum, ditambah berapapun tidak akan merubah keterwakilan (Sugiyono, 2013: 156).

Pengujian yang dilakukan dalam penelitian ini terdiri dari uji instrument, uji asumsi klasik dan regresi linear berganda untuk pengujian hipotesis. Uji instrument 
terdiri dari uji validitas dan uji reliabilitas. Uji validitas dilakukan untuk melihat sejauh mana suatu instrument dapat digunakan untuk mengukur apa yang seharusnya diukur, sedangkan uji reliabilitas digunakan untuk melihat sejauh mana suatu instrument yang bila digunakan beberapa kali untuk mengukur objek yang sama, akan menghasilkan data yang sama. (Sugiyono: 2013).

Uji asumsi klasik dalam penelitian ini menggunakan dua pengujian asumsi yaitu uji asumsi normalitas dan uji asumsi heterokedastisitas. Adapun model regresi linear berganda sebagai berikut:

$$
Y=a+\beta_{1} X_{1}+\beta_{2} X_{2}+\beta_{3} X_{3}+e \ldots
$$

Keterangan :

$$
\begin{array}{ll}
\mathrm{Y} & =\text { Kualitas Audit } \\
\mathrm{a} & =\text { Konstanta } \\
\beta & =\text { Koefisien Regresi } \\
\mathrm{X} 1 & =\text { Prinsip Integritas } \\
\mathrm{X} 2 & =\text { Prinsip Objektivitas } \\
\mathrm{X} 3 & =\text { Prinsip Perilaku Profesional } \\
\mathrm{e} & =\text { Error (Kesalahan Residual) }
\end{array}
$$

\section{HASIL DAN PEMBAHASAN}

\section{Hasil}

\section{Uji Instrumen}

Tabel 1. Uji Validitas prinsip integritas (X1)

\begin{tabular}{cccc}
\hline $\begin{array}{c}\text { No. Butir } \\
\text { Instrumen }\end{array}$ & $\begin{array}{c}\text { Koofesien } \\
\text { Korelasi (r) }\end{array}$ & $\begin{array}{c}\text { Nilai Batas } \\
\text { Korelasi }(\mathrm{r})\end{array}$ & Keterangan \\
\hline X1.1 & 0,871 & 0,3 & Valid \\
X1.2 & 0,58 & 0,3 & Valid \\
X1.3 & $-0,092$ & 0,3 & Tidak Valid \\
\hline
\end{tabular}

Berdasarkan tabel 1 di atas terlihat bahwa X1.3 mempunyai nilai $r_{\text {hitung dibawah }}$ 0,3 sehingga dapat disimpulkan bahwa X1.3 bukan merupakan instrumen yang valid untuk mengukur variabel prinsip integritas. Sedangkan X1.1 dan X1.2 mempunyai 
nilai $\mathrm{r}_{\text {hitung }}$ di atas 0,3 sehingga dapat disimpulkan X1.1 dan X1.2 merupakan instrument yang valid untuk mengukur variabel prinsip integritas.

Tabel 2. Uji Validitas prinsip objektivitas (X2)

\begin{tabular}{cccc}
\hline $\begin{array}{c}\text { No. Butir } \\
\text { Instrumen }\end{array}$ & $\begin{array}{c}\text { Koofesien } \\
\text { Korelasi (r) }\end{array}$ & $\begin{array}{c}\text { Nilai Batas } \\
\text { Korelasi (r) }\end{array}$ & Keterangan \\
\hline X2.1 & 0,543 & 0,3 & Valid \\
X2.1 & 0,736 & 0,3 & Valid \\
X2.3 & 0,304 & 0,3 & Valid \\
\hline
\end{tabular}

Berdasarkan tabel 2 di atas terlihat X2.1, X2.2, dan X2.3 mempunyai nilai rhitung $_{\text {di }}$ atas 0,3 sehingga dapat disimpulkan X2.2 dan X2.3 merupakan instrument yang valid untuk mengukur variabel prinsip objektivitas.

Tabel 3. Uji Validitas prinsip perilaku profesional (X3)

\begin{tabular}{cccc}
\hline $\begin{array}{c}\text { No. Butir } \\
\text { Instrumen }\end{array}$ & $\begin{array}{c}\text { Koofesien } \\
\text { Korelasi (r) }\end{array}$ & $\begin{array}{c}\text { Nilai Batas } \\
\text { Korelasi (r) }\end{array}$ & Keterangan \\
\hline X3.1 & 0,495 & 0,3 & Valid \\
X3.2 & 0,215 & 0,3 & Tidak Valid \\
X3.3 & 0,406 & 0,3 & Valid \\
X3.4 & 0,789 & 0,3 & Valid \\
X3.5 & 0,822 & 0,3 & Valid \\
X3.6 & 0,053 & 0,3 & Tidak Valid \\
X3.7 & 0,589 & 0,3 & Valid \\
X3.8 & 0,404 & 0,3 & Valid \\
X3.9 & 0,83 & 0,3 & Valid \\
X310 & 0,871 & 0,3 & Valid \\
\hline
\end{tabular}

Berdasarkan tabel 3 diatas terlihat bahwa X3.2 dan X3.6 mempunyai nilai $r_{\text {hitung }}$ dibawah 0,3 sehingga dapat disimpulkan bahwa X3.2 dan X3.6 bukan merupakan instrumen yang valid untuk mengukur variabel prinsip objektivitas. Sedangkan selebihnya mempunyai nilai $\mathrm{r}_{\text {hitung }}$ di atas 0,3 sehingga dapat disimpulkan merupakan instrument yang valid untuk mengukur variabel prinsip perilaku profesional.

Tabel 4. Uji Validitas Kualitas audit (Y)

\begin{tabular}{cccc}
\hline $\begin{array}{c}\text { No. Butir } \\
\text { Instrumen }\end{array}$ & $\begin{array}{c}\text { Koofesien } \\
\text { Korelasi (r) }\end{array}$ & $\begin{array}{c}\text { Nilai Batas } \\
\text { Korelasi }(\mathrm{r})\end{array}$ & Keterangan \\
\hline Y.1 & 0,427 & 0,3 & Valid \\
Y.2 & 0,607 & 0,3 & Valid \\
Y.3 & 0,251 & 0,3 & Tidak Valid \\
Y.4 & 0,469 & 0,3 & Valid
\end{tabular}




\begin{tabular}{cccc} 
Y.5 & 0,383 & 0,3 & Tidak Valid \\
Y.6 & 0,441 & 0,3 & Valid \\
\hline
\end{tabular}

Berdasarkan tabel 4 di atas terlihat bahwa Y.3 dan Y.5 mempunyai nilai $r_{\text {hitung }}$ dibawah 0,3 sehingga dapat disimpulkan bahwa Y.1, Y.3 dan Y.5 bukan merupakan instrumen yang valid untuk mengukur variabel prinsip objektivitas. Sedangkan selebihnya mempunyai nilai $r_{\text {hitung }}$ di atas 0,3 sehingga dapat disimpulkan merupakan instrument yang valid untuk mengukur variabel kualitas audit.

Tabel 5. Uji Reliabilitas

\begin{tabular}{cccc}
\hline Variabel & $\begin{array}{c}\text { Koofesien } \\
\text { Reliabilitas } \\
(\alpha)\end{array}$ & $\begin{array}{c}\text { Nilai batas } \\
\text { Alpha }(\alpha)\end{array}$ & Keputusan \\
\hline $\mathrm{X}$ & 0,816 & 0,6 & Reliabel \\
$\mathrm{Y}$ & 0,731 & 0,6 & Reliabel \\
\hline
\end{tabular}

Berdasarkan data pada tabel tersebut di atas menunjukkan bahwa angka-angka dari nilai alpha cronbach's pada variabel independen dan dependen dalam penelitian ini, semuanya menunjukkan besaran diatas nilai 0,60. Hal ini berarti bahwa seluruh pernyataan untuk variabel independen dan dependen adalah reliabel dan dapat disimpulkan bahwa instrumen pernyataan koesioner menunjukkan keandalan dalam mengukur variabel-variabel dalam model penelitian.

\section{Uji Asumsi Klasik}

\section{Uji Asumsi Normalitas}

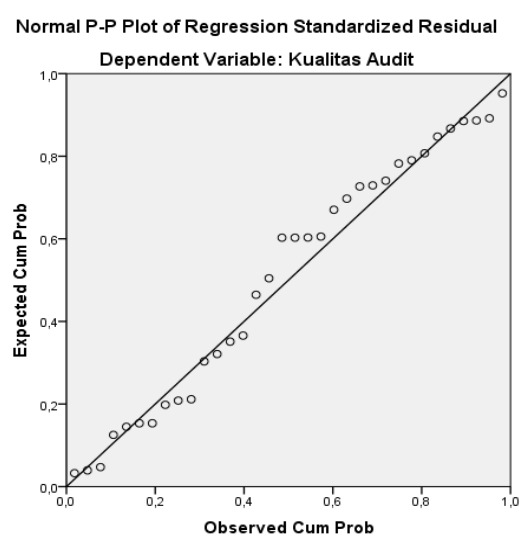

Gambar 1. Hasil uji asumsi normalitas melalui normal P-P plot

Hasil pengujian normalitas dengan menggunakan Normal P-P Plot menunjukkan bahwa titik-titik (dot) menyebar disekitar garis diagonal dan mengikuti arah diagonal, ini menunjukkan bahwa model tersebut telah memenuhi syarat asumsi normalitas. 


\section{Uji Asumsi Heterokedastisitas}

Tabel 6. Hasil uji asumsi heterokedastisitas

\begin{tabular}{rlr}
\multicolumn{2}{c}{ Coefficients $^{\mathrm{a}}$} \\
\hline Model & \multicolumn{1}{c}{ Sig. } \\
\hline & (Constant) & .241 \\
& Prinsip Integritas & .260 \\
1 & Prinsip Objektivitas & .175 \\
& Prinsip Perilaku & .173
\end{tabular}

a. Dependent Variable: kualitas audit

Berdasarkan hasil yang diperoleh pada tabel di atas dapat disimpulkan bahwa residual (error) yang muncul dalam persamaan regresi untuk variabel prinsip integritas, prinsip objektivitas, dan prinsip perilaku profesional dan kualitas audit mempunyai varians yang sama (homokedastisitas) karena hasil pengujian untuk regresi variabel tersebut dengan harga mutlak dari residual (error) tidak signifikan yang ditunjukkan oleh $p$-value $($ sig) $\geq 0,05$ yakni masing-masing untuk prinsip integritas sebesar 0,260 , prinsip objektivitas sebesar 0,175 dan prinsip perilaku profesional sebesar 0,173 dengan demikian pengujian regresi dapat dilanjutkan.

\section{Pengujian Hipotesis}

\section{Metode Regresi Linear Berganda}

Tabel 7. Pengujian persamaan regresi berganda

\begin{tabular}{|c|c|c|c|c|c|c|}
\hline \multirow{2}{*}{\multicolumn{2}{|c|}{ Model }} & \multicolumn{2}{|c|}{$\begin{array}{c}\text { Unstandardized } \\
\text { Coefficients } \\
\end{array}$} & \multirow{2}{*}{$\begin{array}{c}\begin{array}{c}\text { Standardized } \\
\text { Coefficients }\end{array} \\
\text { Beta }\end{array}$} & \multirow[t]{2}{*}{$\mathrm{t}$} & \multirow[t]{2}{*}{ Sig. } \\
\hline & & $\mathrm{B}$ & Std. Error & & & \\
\hline \multirow{4}{*}{1} & (Constant) & 8,465 & 1,664 & & 5,087 & 0 \\
\hline & Prinsip Integritas & $-0,285$ & 0,133 & $-0,46$ & $2139^{-}$ & 0,041 \\
\hline & Prinsip Objektivitas & 0,33 & 0,142 & 0,463 & 2,331 & 0,027 \\
\hline & $\begin{array}{l}\text { Prinsip Perilaku } \\
\text { Profesional }\end{array}$ & 0,096 & 0,049 & 0,369 & 1,958 & 0,06 \\
\hline
\end{tabular}

a. Dependent Variable: Kualitas Audit

Prinsip Integritas memiliki nilai t sebesar $(-2,139)$, nilai koefisien B sebesar (0,285) dan tingkat signifikan sebesar 0,041. Hal ini menandakan bahwa koefisien variabel (X1) Prinsip Integritas memiliki pengaruh negatif sebesar $(-0,285)$ terhadap kualitas audit (Y), tetapi dengan tingkat signifikan sebesar 0,041. Artinya prinsip 
integritas berpengaruh negatif signifikan terhadap kualitas audit karena tingkat signifikansinya di bawah 0,05 .

Prinsip Objektivitas memiliki nilai t sebesar 2,331, nilai koefisien B 0,330 dan tingkat signifikan sebesar 0,027. Hal ini menandakan bahwa koefisien variabel (X2) prinsip objektivitas memiliki pengaruh positif (searah) terhadap kualitas audit (Y) dengan tingkat signifikan 0,027. Artinya prinsip objektivitas berpengaruh positif signifikan terhadap kualitas audit karena di bawah 0,05.

Prinsip perilaku profesional memiliki nilai t sebesar 1,958, nilai koefisien B 0,096 dan tingkat signifikan sebesar 0,060. Hal ini menandakan bahwa koefisien variabel (X3) prinsip perilaku profesional tidak memiliki pengaruh terhadap kualitas audit (Y) dengan tingkat signifikan 0,60. Artinya prinsip perilaku profesional tidak berpengaruh dan tidak signifikan terhadap kualitas auditnya.

Konstanta sebesar 8,465 berarti bahwa seorang auditor tetap dapat memiliki kualitas audit sebesar konstanta meskipun variabel independennya bebas (nol).

\section{Uji Parsial (Uji t)}

Uji t dapat dilihat pada tabel diatas yaitu pada nilai t dengan nilai $\mathrm{df}=\mathrm{n}-\mathrm{k}-1=$ $34-3-1=30$ maka $t_{\text {tabel }}$ diperoleh yaitu 2,0422. Pada tabel 7 nilai Prinsip integritas pada kolom t, nilai thitung lebih besar dari tabel yaitu -2.139>2,0422 maka Ha diterima berarti secara parsial prinsip integritas berpengaruh terhadap kualitas audit, nilai prinsip objektivitas pada kolom t, 2,331 > 2,0422 maka Ha diterima berarti secara parsial prinsip objektivitas berpengaruh terhadap kualitas audit, dan nilai prinsip perilaku professional pada kolom t 1,958 < 2,0422 maka Ha ditolak berarti secara parsial prinsip perilaku profesional tidak berpengaruh terhadap kualitas audit.

Berdasarkan hasil perhitungan ini, dapat pula diperoleh bahwa antara prinsip integritas terhadap kualitas audit terdapat pengaruh negatif dan signifikan pada tingkat kepercayaan $(\alpha=0,05)$. Nilai signifikan diperoleh sebesar 0,041, prinsip objektivitas terhadap kualitas audit terdapat pengaruh positif dan signifikan pada tingkat kepercayaan $(\alpha=0,05)$. Nilai signifikan diperoleh sebesar 0,027 , dan prinsip perilaku profesional terhadap kualitas audit tidak terdapat pengaruh dan tidak signifikan pada tingkat kepercayaan $(\alpha=0,05)$. Nilai signifikan diperoleh sebesar 0,060 . 


\section{Uji Simultan (Uji F)}

Tabel 8. Output $\mathrm{f}_{\text {hitung }}$ pada coefficient

\begin{tabular}{|c|c|c|c|c|c|c|}
\hline \multicolumn{7}{|c|}{ ANOVA $^{a}$} \\
\hline & & $\begin{array}{l}\text { Sum of } \\
\text { Squares }\end{array}$ & Df & $\begin{array}{l}\text { Mean } \\
\text { Square }\end{array}$ & $\mathrm{F}$ & Sig. \\
\hline \multirow{3}{*}{1} & Regression & 13,128 & 3 & 4,376 & 3,538 &, $026^{\mathrm{b}}$ \\
\hline & Residual & 37,107 & 30 & 1,237 & & \\
\hline & Total & 50,235 & 33 & & & \\
\hline
\end{tabular}

\section{a. Dependent Variable: Kualitas Audit}

b. Predictors: (Constant), Prinsip Perilaku Provesional, Prinsip Objektivitas, Prinsip Integritas

Berdasarkan tabel 8. diperoleh $\mathrm{F}$ hitung sebesar 3,538 dengan menggunakan tingkat keyakinan $95 \%$ dan tingkat segnifikan 0,05 , df $1=$ jumlah variable $-1=4-1$ = 3 dan df 2 (n-k-1) atau $30-3$ - 1 = 26, hasil diperoleh untuk F tabel sebesar 2,947. Pada tabel 4.17 nilai $\mathrm{F}$ hitung > F tabel $(3,538$ > 2,947) maka Ho ditolak artinya prinsip integritas, prinsip objektivitas dan prinsip perilaku profesional secara bersama-sama berpengaruh dan signifikan terhadap kualitas audit.

\section{Pembahasan}

Berdasarkan analisis data dan hasil pengujian hipotesis, diperoleh hasil regresi berganda dari penelitian ini bahwa prinsip integritas berpengaruh terhadap kualitas audit. Pengaruh yang timbul adalah negatif, prinsip objektivitas berpengaruh terhadap kualitas audit. Pengaruh yang timbul adalah positif dan pengaruh perilaku professional tidak berpengaruh terhadap kualitas audit.

Hal ini berarti bahwa peningkatan prinsip integritas yang dimiliki seorang auditor mempengaruhi penurunan kualitas auditnya, peningkatan prinsip objektivitas dimilik seorang auditor akan diikuti dengan peningkatan kualitas audit, dan peningkatan prinsip perilaku professional tidak terlalu mempengaruhi penurunan kualitas auditnya. Dengan asumsi faktor-faktor lain yang mempengaruhi besar kecilnya kualitas audit yang dianggap konstan.

Hasil penelitian ini sesuai dengan teori dan berbeda dengan hasil penelitian sebelumnya, hasil penelitian sebelumnya yaitu penelitian Binga dan Jesica (2011), 


\section{Jurnal Ekonomi Pembangunan Vol. 5, No.2 (2019) 89-99}

diketahui bahwa prinsip integritas, prinsip objektivitas, dan prinsip perilaku profesional tidak berpengaruh signifikan terhadap kualitas audit.

\section{KESIMPULAN DAN SARAN}

\section{Kesimpulan}

Berdasarkan dari hasil penelitian dan pembahasan yang dikemukakan sebelumnya, maka kesimpulan dapat dirumuskan berikut ini:

1. Variabel prinsip integritas (X1) berpengaruh negatif dan signifikan terhadap kualitas audit (Y) pada KAP di Kota Makassar.

2. Variabel prinsip objektivitas (X1) tidak berpengaruh positif dan signifikan terhadap kualitas audit (Y) pada KAP di Kota Makassar.

3. Variabel prinsip perilaku professional (X3) tidak berpengaruh dan signifikan terhadap kualitas audit (Y) pada KAP di Kota Makassar.

4. Prinsip integritas (X1), prinsip objektivitas (X2) dan Prinsip perilaku profesional (X3) berpengaruh positif dan signifikan terhadap kualitas audit (Y) KAP di Kota Makassar.

\section{Saran}

Berdasarkan kesimpulan yang dikemukakan sebelumnya, maka peneliti sarankan berikut ini:

1. Auditor independen selayaknya memperhatikan integritas dan objektivitas yang dimilikinya karena hasil penelitian menyatakan bahwa prinsip integritas dan prinsip objektivitas berpengaruh signifikan terhadap kualitas audit. Dengan demikian untuk meningkatkan kualitas audit diperlukan adanya peningkatan integritas dan objektivitas para auditor.

2. Perusahaan yang akan memilih KAP untuk mengaudit laporan keuangannya dapat memilih KAP yang memberikan perhatiannya terhadap kode etik akuntan sehingga diharapkan hasil audit yang diberikan pun sesuai dengan kenyataan yang ada. 


\section{Jurnal Ekonomi Pembangunan Vol. 5, No.2 (2019) 89-99}

Agoes, Sukrisno, 2012. Auditing, Salemba Empat, Jakarta.

Agusti dan Pertiwi, 2013. Pengaruh Kompetensi, Independensi Dan Profesionalisme Terhadap Kualitas Audit. Jurnal Ekonomi, Volume 21 No. 3. Pekanbaru.

Alim, M. Nizarul, dkk, 2007. Pengaruh Kompetensi Dan Independensi Terhadap Kualitas Audit Dengan Etika Auditor Sebagai Variabel Moderasi. Jurnal Akuntansi Auditing. SNA X. Makassar.

Binga Dan Jesica, 2011. Pengaruh Kode Etik Profesi Akuntan Publik Terhadap Kualitas Audit Auditor Independen. Jurnal Akuntansi Kontemporer, Vol. 3 No. 1. Surabaya.

Efendy, Taufik, M, 2010. Pengaruh Kompetensi, Independensi, dan Motivasi Terhadap Kualitas Audit Aparat Inspektorat Dalam Pengawasan Keuangan Daerah. Gorontalo. Tesis : Unoversitas Diponegoro.

Halim, Abdul, 2008. Auditing 1 (Dasar-Dasar Audit Laporan Keuangan), UPP STIM YPKN, Yogyakarta.

IAPI, 2008. Kode Etik Profesi Akuntan Publik, Salemba Empat, Jakarta.

Istijanto, 2006, Riset Sumber Daya Manusia, PT. Gramedia Pustaka Utama, Jakarta.

Kayo, Amrizal S, 2013. Audit Forensik : Penggunaan dan Kompetensi Auditor dalam Pemberantasan Korupsi, Graha Ilmu. Yogyakarta.

Kuncoro, Mudrajad. 2011. Metode Kualitatif : Teori dan Aplikasi untuk Bisnis dan Ekonomi, Edisi Keempat, UPP STIM YKPM, Yogyakarta

Mulyadi. 2013. Auditing 1, Salemba Empat, Jakarta.

Sari, Nungky N, 2011. Pengaruh Pengalaman Kerja, Independensi, Objektivitas,Integritas, Kompetensi Dan Etika Terhadap Kualitas Audit. Semarang. Skripsi : Universitas Diponegoro.

Sunyoto, Danang, 2011. Metode Penelitian untuk Ekonomi. CAPS, Yogyakarta.

Siregar, Sofyan, 2013. Statidtik Parametik untuk Penelitian Kuantitatif Dilengkapi dengan Perhitungan Manual dan Aplikasi SPSS Versi 17, Bumi Aksara, Jakarta.

Sugiyono, 2013. Metode Penelitian Manajemen, Alfabeta, Bandung

Tjun, dkk, 2012. Pengaruh Kompetensi Dan Independensi Auditor Terhadap Kualitas Audit. Bandung. Skripsi : Universitas Kristen Maranatha.

Tuanakota, Theodorus M, 2012. Akuntansi Forensik dan Audit Investigatif, Salemba Empat : Jakarta 